\title{
Treatment Adherence Among Patients with Five Dermatological Diseases and Four Treatment Types - a Cross-Sectional Study
}

This article was published in the following Dove Press journal: Patient Preference and Adherence

\author{
Najlaa Abdulrahman \\ Alsubeeh (iD) ' \\ Aya Ahmed Alsharafi ${ }^{2}$ \\ Shaik Shaffi Ahamed ${ }^{3}$ \\ Abdulmajeed Alajlan (iD ${ }^{4}$ \\ 'College of Medicine, King Saud \\ University, Riyadh, Saudi Arabia; ${ }^{2}$ College \\ of Pharmacy, King Saud University, \\ Riyadh, Saudi Arabia; ${ }^{3}$ Department of \\ Family and Community Medicine, College \\ of Medicine, King Saud University, Riyadh, \\ Saudi Arabia; ${ }^{4}$ Department of \\ Dermatology, College of Medicine, King \\ Saud University, Riyadh, Saudi Arabia
}

Correspondence: Abdulmajeed Alajlan King Saud University, Riyadh, Saudi Arabia Tel +966502223030

Email amajlan@ksu.edu.sa
Purpose: Treatment non-adherence leads to negative therapeutic outcomes and financial burdens on the healthcare system. This study aims to compare the mean adherence scores among patients with five dermatological diseases and four treatment types and to identify the associated patient-related factors.

Patients and methods: This is a cross-sectional study conducted from January 2019 to August 2019. The questionnaire was distributed among patients attending the outpatient dermatology clinic at King Khalid University Hospital, Riyadh, Saudi Arabia. It included 2330 patients who were over 16 years old and diagnosed with any of the five dermatological diseases (psoriasis, chronic dermatitis, acne vulgaris, hair growth disorders, and vitiligo). The 12-item Medication Adherence Scale was used to quantify the mean adherence score.

Results: Patients with psoriasis or chronic dermatitis were less adherent to treatments than patients with acne vulgaris, hair growth disorder, or vitiligo. Oral treatment and phototherapy had higher mean adherence scores than injection or topical treatment. High adherence was found in female, single patients; those who did not feel stigmatized from using treatment; those who did not have bad experience with the treatment; those who did not suffer from forgetfulness; those who connected receiving treatment with a habit; those who did not lack treatment responsiveness; those who had an excellent relationship with a dermatologist; and patients with a lesion in an exposed area. Stepwise multiple linear regression was also used to identify the independent variables related to adherence score.

Conclusion: Psoriasis and chronic dermatitis patients had the lowest mean adherence scores. Patient who were on oral medication had the highest adherence score, while those on topical medication had the lowest score. The thoughtful consideration of factors associated with high adherence is important for optimal therapeutic outcomes.

Keywords: adherence, treatment, psoriasis, dermatitis, acne, vitiligo

\section{Introduction}

Adherence occurs when patients actively participate in their treatment plans and take their treatments as recommended by their healthcare providers. ${ }^{1}$ Good adherence is related to good therapeutic outcomes in various chronic diseases. ${ }^{2-4}$ Conversely, poor adherence is associated with treatment failure and a relapse of disease. $^{5}$ A recent systematic review reported that medication non-adherence is considered as a major cost burden on the healthcare system. ${ }^{5}$ In dermatological diseases, non-adherence to treatment is problematic and related to negative therapeutic outcomes. ${ }^{6-9}$ About $50 \%$ of patients diagnosed with chronic skin diseases 
were not adherent to the treatments prescribed by their dermatologists. ${ }^{10}$ There are many different treatment types of treatments for patients with dermatological diseases, including topical therapy, systemic therapy (orally or by injection), and phototherapy. Previous studies have assessed adherence to topical treatments and reported low non-adherence scores. ${ }^{11,12}$ In 2018, a Japanese study reported a low adherence of $56.4 \%$ for their psoriatic patients using topical treatments. ${ }^{11}$ Adherence to oral therapy was higher than adherence to topical therapy. ${ }^{13}$ Another study reported that $55.4 \%$ of patients taking oral therapy had low adherence and reported a higher percentage of low adherence for patients taking topical therapy (76.4\%). ${ }^{14}$ However, another study showed that good adherence was only seen in $32.6 \%$ of patients who were taking oral therapy to manage psoriasis. ${ }^{11}$ Concerning the level of adherence to injection among patients with psoriasis, a large study of 2707 patients investigated their adherence to biologic agents. The study found that $37.7 \%$ of patients demonstrated a low level of adherence to treatment. ${ }^{15}$ On the contrary, another study showed a higher level of adherence to biologics (93.5\%). ${ }^{16}$ Similarly, it has been reported that adherence to biologics ranked significantly better $(100 \%)$ when compared to the adherence to other treatment types (topical, oral, and phototherapy). ${ }^{17}$ Another treatment type is phototherapy, and its adherence rate was assessed among patients with vitiligo or psoriasis. ${ }^{18-21}$ According to the results of two published studies, the adherence to psoriasis phototherapy treatment was $25 \%$ and $47 \%,{ }^{18,19}$ whereas other studies showed that adherence to vitiligo phototherapy treatment was $26.58 \%, 29 \%$, and $61 \%$, respectively. ${ }^{19-21}$

Since non-adherence is associated with negative outcomes, it is crucial to tackle this phenomenon and ultimately maximize positive treatment outcomes by a thorough understanding of the risk factors associated with treatment non-adherence. To the best of our knowledge, there is a paucity of comparative studies that have compared the mean adherence score among four treatment types (topical, oral, injection, and phototherapy) and among five dermatological diseases (vitiligo, psoriasis, chronic dermatitis, acne vulgaris, and hair growth disorders). Furthermore, treatment adherence in Saudi patients with dermatological diseases has been identified as a major research gap in the literature. In order to address this gap, this study compared the mean adherence scores among different treatment types prescribed by dermatologist (including oral, topical, injection, and phototherapy) and among five dermatological diseases (including acne vulgaris, chronic dermatitis, psoriasis, vitiligo, and hair growth disorders) using a 12-item Medication Adherence Scale, and it identified possible patient-related factors affecting adherence to dermatological treatment.

\section{Materials And Methods}

\section{Subjects And Methods}

This is a cross-sectional, questionnaire-based study that was conducted in Saudi Arabia from January 2019 to August 2019. It was distributed among patients attending the outpatient dermatology and phototherapy clinics at King Khalid University Hospital, Riyadh. In total, 7500 questionnaires were distributed, and valid responders were selected. A simple random sample of $2330(50 \%$ of the valid participants) was involved in data analysis as part of the statistical reliability standard method. This study included patients who agreed to participate; were Saudi; aged between 17 and 65 years old; were on any treatment prescribed by a dermatologist for a month and above; were on any of the following treatment types: phototherapy, injection therapy, topical therapy, and oral therapy; and who were diagnosed with either psoriasis, chronic dermatitis, acne vulgaris, hair growth disorders, or vitiligo.

\section{Study Questionnaire}

The study questionnaire consisted of five sections. The first section included screening questions to determine the eligibility of the participants to take part in the study according to the inclusion and exclusion criteria. The second section was used to measure treatment adherence in patients with dermatological diseases using the 12Item Medication Adherence Scale, which was developed by Haruka Ueno. ${ }^{22}$ The scale included 12 items and it consists of four categories, each containing three items to measure factors associated with medication adherence. The first category was to measure treatment compliance, the second to measure collaboration with healthcare providers, the third to measure willingness to access and use information about treatment, and the fourth to measure acceptance to take treatment and how taking treatment fits patients' lifestyles. A five-point Likert-type scale was used to rate each item from 1 (never) to 5 (always). The overall medication adherence score was calculated after summing the scores for each item. The maximum score of this scale is 60 . The higher scores indicated higher medication adherence. ${ }^{22}$ 
The third and fourth sections of the questionnaire included possible patient-related factors for nonadherence for treatments in patients with dermatological diseases. Patient-related factors include stigma from using medication; fear of medication side effects; forgetfulness; feeling cured of the dermatological disease; busy lifestyle; connecting taking treatment with a well-established habit; previous bad experiences with the treatment; lack of treatment responsiveness; patient satisfaction with treatment; patient-dermatologist relationship; adequate information provided by a dermatologist about the disease and the location of dermatologic disease. The fifth section of the questionnaire contained questions on patients' sociodemographic data (includes age, gender, marital status, and educational level).

Permission was obtained from the developer to use the 12Item Medication Adherence Scale. ${ }^{22}$ Before the translation, we received permission from the developer to change the word "medication" to "treatment" because the word "treatment" is more applicable to the phototherapy. The developer gave permission for the change since phototherapy is a longterm treatment and under the voluntary intention of the patient. Forward translation of the questionnaire was carried out by two researchers with medical backgrounds. They independently translated the original English items into Arabic and then combined the translations into a single Arabic translation. Two further bilingual translators carried out the backward translation into English. A final English translation of each item was sent to the original author, and his approval was obtained. Eventually, the final Arabic translation was tested on 10 patients as a pilot trial to check the clarity and comprehensiveness of the questionnaire. Afterward, a pilot trial was conducted on 20 patients to calculate the Cronbach alpha to measure the reliability of the scale items.

\section{Data Analysis}

Data were analyzed using the Statistical Package for Social Studies (IBM Corp. Released 2013. IBM SPSS Statistics for Windows, Version 22.0. Armonk, NY: IBM Corp). Continuous variables were expressed as mean \pm standard deviation, and categorical variables were expressed as percentages. The $t$-test and one-way ANOVA were used for to compare the mean values of adherence score in relation to the categorical variable with 2 and more than 2 categories. A p-value was deemed statistically significant at $\mathrm{P}<00.05$. Stepwise multiple linear regression was used to identify the independent variables related to adherence score. Cronbach's alpha index was applied for internal consistency reliability. The acceptable value of the index is considered to in the range of 0.70 to 0.95 . $^{23}$

\section{Ethical Consideration}

The present study was approved by the Institutional Review Board (IRB) of the College of Medicine, King Saud University. Written informed consent was obtained from all study participants before the commencement of the questionnaire. All information collected in the study was confidential and was not used for other purposes. Respondent anonymity was maintained as no name or identifying information was required in order to respond.

\section{Results}

Out of the 7500 respondents who were approached for the study, the 4660 who fulfilled the criteria of the study exhibited a response rate of $61.86 \%$. A simple random sample of 2330 out of the $4660(50 \%)$ was selected for statistical analysis purposes. Out of the 2330 study subjects, $82.4 \%$ are below the age of 30 years, with a mean age of 25.3 years. Of the subject group, $79.5 \%$ are female, $72.9 \%$ are single, $77.8 \%$ have at least a university level of education. Regarding their conditions, the majority suffer from acne vulgaris $(38.5 \%)$, followed by chronic dermatitis $(25.9 \%)$, hair growth disorders $(12.9 \%)$, vitiligo (11.4\%), and psoriasis (11.3\%). More than $50 \%$ of the study subjects are following topical treatment, $24.5 \%$ are using oral treatment, $7.9 \%$ are on phototherapy, and $5.1 \%$ are on injection treatment. The duration of treatment is 1 to 3 months in $31.4 \%$ and $>12$ months in $33.5 \%$ of study subjects, as shown in Table 1.

The mean adherence score of the study population was 44.93. The overall reliability score of the 12-Item Medication Adherence Scale is 0.788 , which demonstrates a very good reliability score of this scale. Out of the five dermatological conditions (psoriasis, chronic dermatitis, acne vulgaris, hair growth disorders, and vitiligo), the mean adherence scores are statistically significantly higher in patients who are suffering from acne vulgaris, followed by in those who have hair growth disorders and vitiligo. Moreover, the mean adherence scores are statistically the lowest in patients who are suffering from chronic dermatitis and psoriasis $(p<0.001)$. Regarding the treatment types, the adherence is statistically higher in patients who are using oral treatment and phototherapy, compared to those who are using injection and topical types of treatment $(\mathrm{p}<0.001)$, as shown in Table 2 . 
Table I Demographic And Characteristics Of Study Subjects $(n=2330)$

\begin{tabular}{|c|c|c|c|}
\hline $\begin{array}{l}\text { Name Of } \\
\text { Variable }\end{array}$ & & Frequency & (Percent \%) \\
\hline Nationality & $\begin{array}{l}\text { Saudi } \\
\text { Non-Saudi }\end{array}$ & $\begin{array}{l}2330 \\
0.00\end{array}$ & $\begin{array}{l}(100.0) \\
(0.00)\end{array}$ \\
\hline Age (years) & $\begin{array}{l}\text { (Mean*Std. } \\
\text { Deviation**) } \\
\leq 20 \\
21-30 \\
3 I-40 \\
4 I-50 \\
>50\end{array}$ & $\begin{array}{l}25.30 * \\
733 \\
1186 \\
272 \\
92 \\
47\end{array}$ & $\begin{array}{l}(8.098)^{* *} \\
(31.5) \\
(50.9) \\
(11.7) \\
(3.9) \\
(2.0)\end{array}$ \\
\hline Gender & $\begin{array}{l}\text { Female } \\
\text { Male }\end{array}$ & $\begin{array}{l}1852 \\
478\end{array}$ & $\begin{array}{l}(79.5) \\
(20.5)\end{array}$ \\
\hline Marital status: & $\begin{array}{l}\text { Single } \\
\text { Married } \\
\text { Divorced } \\
\text { Widowed }\end{array}$ & $\begin{array}{l}1699 \\
565 \\
50 \\
16\end{array}$ & $\begin{array}{l}(72.9) \\
(24.2) \\
(2.1) \\
(0.7)\end{array}$ \\
\hline $\begin{array}{l}\text { Educational } \\
\text { status: }\end{array}$ & $\begin{array}{l}\text { High school and } \\
\text { below } \\
\text { University and } \\
\text { above }\end{array}$ & $\begin{array}{l}518 \\
1812\end{array}$ & $\begin{array}{l}(22.2) \\
(77.8)\end{array}$ \\
\hline $\begin{array}{l}\text { Dermatological } \\
\text { conditions }\end{array}$ & $\begin{array}{l}\text { Acne vulgaris } \\
\text { Hair growth } \\
\text { disorder } \\
\text { Vitiligo } \\
\text { Chronic } \\
\text { Dermatitis } \\
\text { Psoriasis }\end{array}$ & $\begin{array}{l}897 \\
301 \\
265 \\
603 \\
264\end{array}$ & $\begin{array}{l}(38.5) \\
(12.9) \\
(11.4) \\
(25.9) \\
(11.3)\end{array}$ \\
\hline Treatment type & $\begin{array}{l}\text { Phototherby } \\
\text { Injection } \\
\text { Topical } \\
\text { Oral }\end{array}$ & $\begin{array}{l}183 \\
118 \\
1459 \\
570\end{array}$ & $\begin{array}{l}(7.9) \\
(5.1) \\
(62.6) \\
(24.5)\end{array}$ \\
\hline $\begin{array}{l}\text { Duration of } \\
\text { treatment }\end{array}$ & $\begin{array}{l}\text { From I to } 3 \\
\text { months } \\
>3 \text { to } 6 \text { months } \\
>6 \text { to } 9 \text { months } \\
>9 \text { months to } \\
12 \text { months } \\
>12 \text { months }\end{array}$ & $\begin{array}{l}731 \\
442 \\
232 \\
145 \\
780\end{array}$ & $\begin{array}{l}(31.4) \\
(19.0) \\
(10.0) \\
(6.2) \\
(33.5)\end{array}$ \\
\hline
\end{tabular}

Notes: Mean $(*)$. Standard deviation (**).

The comparison of mean adherence scores in relation to the sociodemographic characteristics of study subjects shows highly statistically significant differences for female subjects with higher adherence mean scores $(p<0.0001)$ and for the single patients compared to the married ones $(\mathrm{p}<0.001)$. Age and educational status showed no effect on adherence scores, as shown in Table 3 .
Out of the patient-related factors studied, feeling to be stigmatized from using treatment; bad experience with the treatment; forgetfulness; improved condition; lack of treatment responsiveness; connect taking treatment with a wellestablished habit; patient-dermatologist relationship; and location of dermatological disease show statistically significant difference in the mean adherence scores, whereas patients who did not feel stigmatized from using their treatment show high adherence mean scores with $\mathrm{p}$ value $<0.0001$. Participants who did not have a previous bad experience with the treatment have a high mean adherence score compared to the other group $(\mathrm{p}<0.0001)$. Subjects who did not report "forgetfulness" as a factor towards the adherence have higher mean adherence score compared to those who report forgetfulness. In addition, lack of treatment responsiveness is statistically associated with low mean adherence score $(\mathrm{P}<0.0001)$. Patients who connecting treatment with a well-established habit are significantly associated with higher mean adherence score compared to subjects who are not $(\mathrm{p}<0.0001)$.

Patient satisfaction with treatment is statistically associated with high adherence mean score $(\mathrm{P}<0.0001)$. Also, the mean adherence scores are statistically significantly higher in those subjects whose patient-dermatologist relationship is reported to be excellent and good when compared to the scores of those whose relationships with their dermatologists are poor $(p<0.0001)$. The duration of treatment, which was categorized into five categories ranging from 1 to 3 months and up to greater than 12 months, has a statistically significant effect on the medication adherence scores. The mean adherence scores are statistically significantly higher in patients who are taking the treatment between 1 to 3 months, 3 to 6 months, and 6 to 9 months, compared to the patients who are taking treatment between 9 and 12 months and $>12$ months $(p<0.0001)$. The dermatological diseases in the exposed area of patient's body shows a statistically significant higher mean adherence scores compared with the subjects who had a dermatological disease in the unexposed area $(\mathrm{p}<0.0001)$, as shown in Table 3 .

The stepwise multiple regression analysis reveals a statistically significant relationship between the study variables (Non adherence due to improved condition, Patient \& Dermatologist relationship(poor), Patient \& Dermatologist relationship (good), lack of responsiveness, forgetfulness, connect taking treatment with a habit, location of area (unexposed), Stigmatized, Satisfaction with treatment, gender (Female) and duration of treatment (9 to 12 months). The 
Table 2 Comparison of Medication Adherence Mean Score in Relation to The Dermatological Condition and Treatment Type of Study Subjects $(n=2330)$

\begin{tabular}{|l|l|l|l|l|}
\hline Variables & Frequency (Percent \%) & $\begin{array}{l}\text { Medication Adherence Score } \\
\text { Mean (Std. Deviation) }\end{array}$ & F-value & p-value \\
\hline $\begin{array}{l}\text { Dermatological conditions } \\
\text { Acne vulgaris }\end{array}$ & $897(38.5)$ & $47.45(7.388)$ & 43.511 \\
Hair growth disorder & $301(12.9)$ & $44.72(7.583)$ & 0.000 \\
Vitiligo & $265(11.4)$ & $44.52(8.799)$ & \\
Chronic Dermatitis & $603(25.9)$ & $42.63(7.774)$ & \\
Psoriasis & $264(11.3)$ & $42.24(9.131)$ & 36.487 \\
\hline Treatment type & $183(7.9)$ & $46.28(9.031)$ & \\
Phototherby & $118(5.1)$ & $44.54(8.639)$ & \\
Injection & $1459(62.6)$ & $43.70(7.811)$ & \\
Topical & $570(24.5)$ & $47.72(7.978)$ & \\
Oral & & & \\
\hline
\end{tabular}

final model with these variables is highly statistically significant $(\mathrm{F}=63.885, \mathrm{p}<0.0001)$. The $\mathrm{R}$-squared value of 0.306 indicates that approximately $30.6 \%$ of the changes in the adherence scores are explained by these variables. The R-squared change from model one to model 16 is also statistically significant. Furthermore, the regressions coefficients of these study variables are statistically significant. The other variables (age groups, marital status, bad experience with treatment, duration of treatment 3 to 6 months, duration of treatment 6 to 9 months, duration of treatment $>12$ months) are not statistically significantly related to the adherence scores. (Table 4)

\section{Discussion}

This study investigates treatment adherence in Saudi patients with dermatological diseases using a translated Arabic version of a 12-Item Medication Adherence Scale. There is a paucity of comparative studies that have compared the level of adherence among five dermatological diseases and four treatment types. Nonadherence to treatment is a common problem in patients with dermatological diseases. In our study, treatment adherence mean values were compared based upon the type of treatment. Two previous studies have indicated that adherence to oral treatment is significantly higher than that to topical treatment among patients with dermatological diseases. ${ }^{13,24}$ The present study supports their finding where the mean adherence to oral medication (47.72), phototherapy (46.28) and injections (44.54) are higher than adherence to topical treatment (43.70), as assessed using the 12-Item Medication Adherence Scale. This finding might be attributed to the unappealing attributes of topical medication, such as the unpleasant smell and greasiness, which make patients reluctant to adhere to their use. Moreover, patients on injection treatments and phototherapy are more likely to suffer from a more severe course of dermatological conditions compared to patients on topical medication, and therefore those patients may be more motivated to adhere to their treatment. However, a study performed among psoriatic patients found compliance to be the highest in systemic therapy (97\%) compared to in phototherapy $(90 \%)$ and topical therapy $(51 \%){ }^{25}$ Similarly, another study conducted among psoriatic patients showed that adherence was significantly better for biologics (100\%), followed by oral medication (96\%), phototherapy (93\%), and topical medication $(75 \%) .{ }^{17}$ We observed some variation from what has been published in the literature. It could be due to the differences in cultural background of study populations and the heterogeneity of assessment methods or scales used in measuring the treatment adherence in each study.

The current study also compared adherence means among different dermatological diseases (acne vulgaris, hair growth disorders, vitiligo, psoriasis, and chronic dermatitis) using the 12-Item Medication Adherence Scale. Out of these dermatological diseases, psoriasis (42.24) and chronic dermatitis patients (42.63) have the lowest mean adherence score. Such findings are in line with a recent Chinese study (in 2018), which demonstrated poor adherence to treatment among psoriasis patients $(41.5 \%){ }^{26}$ Moreover, a Japanese study found that adherence to medication (oral or topical) in patients with atopic dermatitis was generally lower than in those with psoriasis or tinea. ${ }^{13}$ Topical corticosteroids are usually used as a first-line 
Table 3 Comparison Of Medication Adherence Mean Score In Relation To Socio-Demographic Characteristics Of Study Subjects And Patient Related Factors $(n=2330)$

\begin{tabular}{|c|c|c|c|c|c|c|c|}
\hline Characteristics & & Frequency & (Percent \%) & $\begin{array}{l}\text { Medication } \\
\text { Adherence } \\
\text { Score Mean }\end{array}$ & $\begin{array}{l}\text { (Std. } \\
\text { Deviation) }\end{array}$ & $\begin{array}{l}\text { F-valuel } \\
\text { t-value* }\end{array}$ & p-value \\
\hline Age (years) & $\begin{array}{l}\leq 20 \\
21-30 \\
31-40 \\
4 I-50 \\
>50\end{array}$ & $\begin{array}{l}733 \\
1186 \\
272 \\
92 \\
47\end{array}$ & $\begin{array}{l}(31.5) \\
(50.9) \\
(11.7) \\
(3.9) \\
(2.0)\end{array}$ & $\begin{array}{l}45.05 \\
45.14 \\
44.31 \\
43.47 \\
44.09\end{array}$ & $\begin{array}{l}(7.970) \\
(8.179) \\
(8.474) \\
(8.291) \\
(9.165)\end{array}$ & 1.490 & 0.203 \\
\hline Gender & $\begin{array}{l}\text { Female } \\
\text { Male }\end{array}$ & $\begin{array}{l}1852 \\
478\end{array}$ & $\begin{array}{l}(79.5) \\
(20.5)\end{array}$ & $\begin{array}{l}45.38 \\
43.15\end{array}$ & $\begin{array}{l}(7.943) \\
(8.815)\end{array}$ & $5.348^{*}$ & $<0.0001$ \\
\hline Marital status: & $\begin{array}{l}\text { Single } \\
\text { Married } \\
\text { Divorced } \\
\text { Widowed }\end{array}$ & $\begin{array}{l}1699 \\
565 \\
50 \\
16\end{array}$ & $\begin{array}{l}(72.9) \\
(24.2) \\
(2.1) \\
(0.7)\end{array}$ & $\begin{array}{l}45.35 \\
43.73 \\
44.58 \\
43.63\end{array}$ & $\begin{array}{l}(8.039) \\
(8.444) \\
(8.890) \\
(7.293)\end{array}$ & 5.760 & 0.001 \\
\hline Educational status: & $\begin{array}{l}\text { High school and below } \\
\text { University and above }\end{array}$ & $\begin{array}{l}518 \\
1812\end{array}$ & $\begin{array}{l}(22.2) \\
(77.8)\end{array}$ & $\begin{array}{l}44.81 \\
44.96\end{array}$ & $\begin{array}{l}(8.599) \\
(8.055)\end{array}$ & $-0.357^{*}$ & 0.721 \\
\hline $\begin{array}{l}\text { Feeling to be stigmatized from using } \\
\text { treatment }\end{array}$ & $\begin{array}{l}\text { Yes } \\
\text { No }\end{array}$ & $\begin{array}{l}281 \\
2049\end{array}$ & $\begin{array}{l}(12.1) \\
(87.9)\end{array}$ & $\begin{array}{l}41.23 \\
45.43\end{array}$ & $\begin{array}{l}(8.202) \\
(8.045)\end{array}$ & $-8.189 *$ & $>0.0001$ \\
\hline Fear of treatment side effects & $\begin{array}{l}\text { Yes } \\
\text { No }\end{array}$ & $\begin{array}{l}1145 \\
1185\end{array}$ & $\begin{array}{l}(49.1) \\
(50.9)\end{array}$ & $\begin{array}{l}45.00 \\
44.85\end{array}$ & $\begin{array}{l}(8.028) \\
(8.323)\end{array}$ & $0.45 I^{*}$ & 0.652 \\
\hline Bad experience with the treatment & $\begin{array}{l}\text { Yes } \\
\text { No }\end{array}$ & $\begin{array}{l}538 \\
1792\end{array}$ & $\begin{array}{l}(23.1) \\
(76.9)\end{array}$ & $\begin{array}{l}43.50 \\
45.35\end{array}$ & $\begin{array}{l}(8.258) \\
(8.107)\end{array}$ & $-4.631^{*}$ & $<0.0001$ \\
\hline Forgetfulness & $\begin{array}{l}\text { Yes } \\
\text { No }\end{array}$ & $\begin{array}{l}1665 \\
665\end{array}$ & $\begin{array}{l}(71.5) \\
(28.5)\end{array}$ & $\begin{array}{l}43.60 \\
48.25\end{array}$ & $\begin{array}{l}(8.066) \\
(7.487)\end{array}$ & $-12.827 *$ & $<0.0001$ \\
\hline $\begin{array}{l}\text { Non-adherence due to improved } \\
\text { condition }\end{array}$ & $\begin{array}{l}\text { Yes } \\
\text { No }\end{array}$ & $\begin{array}{l}1183 \\
1147\end{array}$ & $\begin{array}{l}(50.8) \\
(49.2)\end{array}$ & $\begin{array}{l}42.57 \\
47.35\end{array}$ & $\begin{array}{l}(7.843) \\
(7.803)\end{array}$ & $-14.732 *$ & $<0.0001$ \\
\hline Lack of treatment responsiveness & $\begin{array}{l}\text { Yes } \\
\text { No }\end{array}$ & $\begin{array}{l}760 \\
1570\end{array}$ & $\begin{array}{l}(32.6) \\
(67.4)\end{array}$ & $\begin{array}{l}42.22 \\
46.24\end{array}$ & $\begin{array}{l}(7.937) \\
(7.97 I)\end{array}$ & $-11.412^{*}$ & $<0.0001$ \\
\hline Busy lifestyle & $\begin{array}{l}\text { Yes } \\
\text { No }\end{array}$ & $\begin{array}{l}1535 \\
795\end{array}$ & $\begin{array}{l}(65.9) \\
(34.1)\end{array}$ & $\begin{array}{l}44.79 \\
45.19\end{array}$ & $\begin{array}{l}(8.174) \\
(8.183)\end{array}$ & $-1.144 *$ & 0.253 \\
\hline Connect taking treatment with a habit & $\begin{array}{l}\text { Yes } \\
\text { No }\end{array}$ & $\begin{array}{l}1454 \\
876\end{array}$ & $\begin{array}{l}(62.4) \\
(37.6)\end{array}$ & $\begin{array}{l}45.95 \\
43.23\end{array}$ & $\begin{array}{l}(7.744) \\
(8.590)\end{array}$ & $7.884 *$ & $<0.0001$ \\
\hline Satisfaction with treatment & $\begin{array}{l}\text { Yes } \\
\text { No }\end{array}$ & $\begin{array}{l}1563 \\
767\end{array}$ & $\begin{array}{l}(67.1) \\
(32.9)\end{array}$ & $\begin{array}{l}46.23 \\
42.27\end{array}$ & $\begin{array}{l}(8.010) \\
(7.872)\end{array}$ & $11.275^{*}$ & $<0.0001$ \\
\hline Patient-dermatologist relationship & $\begin{array}{l}\text { Excellent } \\
\text { Good } \\
\text { Poor }\end{array}$ & $\begin{array}{l}750 \\
1108 \\
472\end{array}$ & $\begin{array}{l}(32.2) \\
(47.6) \\
(20.3)\end{array}$ & $\begin{array}{l}47.89 \\
44.73 \\
40.66\end{array}$ & $\begin{array}{l}(7.898) \\
(7.610) \\
(7.940)\end{array}$ & 125.975 & $<0.0001$ \\
\hline Duration of treatment & $\begin{array}{l}\text { From } 1 \text { to } 3 \text { months } \\
>3 \text { to } 6 \text { months } \\
>6 \text { to } 9 \text { months } \\
>9 \text { months to } 12 \text { months } \\
>12 \text { months }\end{array}$ & $\begin{array}{l}731 \\
442 \\
232 \\
145 \\
780\end{array}$ & $\begin{array}{l}(31.4) \\
(19.0) \\
(10.0) \\
(6.2) \\
(33.5)\end{array}$ & $\begin{array}{l}46.15 \\
45.98 \\
45.90 \\
43.97 \\
43.07\end{array}$ & $\begin{array}{l}(7.752) \\
(8.114) \\
(8.149) \\
(8.379) \\
(8.232)\end{array}$ & 17.743 & $<0.0001$ \\
\hline Location of dermatological disease & $\begin{array}{l}\text { Exposed area } \\
\text { Unexposed area } \\
\text { Both }\end{array}$ & $\begin{array}{l}1204 \\
179 \\
947\end{array}$ & $\begin{array}{l}(51.7) \\
(7.7) \\
(40.6)\end{array}$ & $\begin{array}{l}45.29 \\
41.55 \\
45.10\end{array}$ & $\begin{array}{l}(8.180) \\
(8.092) \\
(8.055)\end{array}$ & 16.905 & $<0.0001$ \\
\hline
\end{tabular}

Note: T-value $(*)$. 
Table 4 Independent Variables Related To The Adherence Score Using Stepwise Multiple Regression Analysis

\begin{tabular}{|c|c|c|c|c|c|c|c|}
\hline \multirow[t]{2}{*}{ Model } & \multicolumn{2}{|c|}{$\begin{array}{l}\text { Unstandardized } \\
\text { Coefficients }\end{array}$} & \multirow{2}{*}{$\begin{array}{l}\text { Standardized } \\
\text { Coefficients } \\
\text { Beta }\end{array}$} & \multirow[t]{2}{*}{ t-value } & \multirow[t]{2}{*}{ p-value } & \multicolumn{2}{|c|}{$\begin{array}{l}95.0 \% \text { Confidence } \\
\text { Interval for B }\end{array}$} \\
\hline & B & $\begin{array}{l}\text { Std. } \\
\text { Error }\end{array}$ & & & & $\begin{array}{l}\text { Lower } \\
\text { Bound }\end{array}$ & $\begin{array}{l}\text { Upper } \\
\text { Bound }\end{array}$ \\
\hline (Constant) & 53.385 & 0.509 & & 104.956 & $<0.0001$ & 52.388 & 54.383 \\
\hline Non-adherence due to improved condition(Yes) & -3.673 & 0.300 & -0.225 & -12.244 & $<0.0001$ & -4.261 & -3.085 \\
\hline Patient Dermatologist Relationship(Poor) & -4.980 & 0.430 & -0.245 & -11.572 & $<0.0001$ & -5.824 & -4.136 \\
\hline Lack of responsiveness(Yes) & -1.892 & 0.341 & -0.109 & -5.544 & $<0.0001$ & -2.562 & -1.223 \\
\hline Forgetfulness(Yes) & -2.804 & 0.331 & -0.155 & -8.462 & $<0.0001$ & -3.454 & -2.154 \\
\hline Connect taking treatment with a habit $(\mathrm{No})$ & -2.079 & 0.298 & 0.123 & -6.974 & $<0.0001$ & -2.664 & -1.494 \\
\hline Location of dermatological disease area (Unexposed) & -2.622 & 0.571 & -0.085 & -4.595 & $<0.0001$ & -3.741 & -1.503 \\
\hline Patient Dermatologist Relationship(Good) & -2.100 & 0.336 & -0.128 & -6.251 & $<0.0001$ & -2.759 & -1.442 \\
\hline Stigmatized(Yes) & -2.159 & 0.455 & -0.086 & -4.742 & $<0.000$ I & -3.051 & -1.266 \\
\hline Dermatological Condition (Atopic Dermatitis) & -2.600 & 0.373 & -0.139 & -6.965 & $<0.0001$ & -3.332 & -1.868 \\
\hline Satisfaction with treatment & -1.523 & 0.346 & -0.088 & -4.408 & $<0.0001$ & -2.201 & -0.845 \\
\hline Gender(Female) & 1.163 & 0.364 & 0.057 & 3.190 & 0.001 & 0.448 & 1.878 \\
\hline Dermatological Condition (Psoriasis) & -2.580 & 0.519 & -0.100 & -4.967 & $<0.0001$ & -3.599 & -1.562 \\
\hline Dermatological Condition (Hair growth disorder) & -1.418 & 0.463 & -0.058 & -3.062 & 0.002 & -2.326 & -0.510 \\
\hline Dermatological Condition(Vitiligo) & -1.508 & 0.517 & -0.059 & -2.918 & 0.004 & -2.521 & -0.494 \\
\hline Duration of Treatment (9tol2months) & -1.258 & 0.589 & -0.037 & -2.138 & 0.033 & -2.413 & -0.104 \\
\hline Location of dermatological disease area (Both) & 0.621 & 0.313 & 0.037 & 1.983 & 0.047 & 0.007 & 1.235 \\
\hline
\end{tabular}

defense in treating chronic dermatitis. Some patients have fear and misconceptions about using this type of medication (known as "steroid phobia"), which may play a major role in non-adherence to chronic dermatitis treatment. ${ }^{27}$ Acne vulgaris and hair disorders patients are more adherent to their medication, which might be due to the common occurrence of lesions in exposed areas that is common in both of these dermatological conditions. Hence, patients are more motivated to adhere to their medication. However, there is a lack of information about adherence to treatment among hair disorders patients in the literature, which limited the comparability with any other study.

This paper also provides insight into possible patientrelated factors associated with high treatment adherence. Our findings showed that being female significantly correlated with having a high adherence mean score for treatment. This finding is consistent with a study conducted by Ali et al in which females showed high adherence to their vitiligo medication. ${ }^{28}$ Similarly, a study conducted by Haruka et al showed that female patients with chronic diseases have higher mean adherence scores than male patients. ${ }^{22}$ In contrast, Yildiz et al found that no significant correlation was observed between gender and adherence among acne vulgaris patients. ${ }^{29}$ Similarly, another study did not reveal a significant association between gender and adherence in psoriatic patients. ${ }^{26}$ Female patients seemed more adhered to their treatment due to greater consciousness of their appearance.

The current study shows that forgetfulness was one of the major reasons for non-adherence to treatment. A study found a similar result in atopic dermatitis patients. ${ }^{30} \mathrm{We}$ also noticed that patients who connect taking treatment with a habit, such as prayer time, brush teeth, or using an alarm clock application, showed higher adherence mean scores. This finding could be a helpful way to solve the forgetfulness problem.

According to our findings, patients who have been taking a treatment for a period between 1 to 3 months are more adherent to their medication than those with higher treatment duration. This is supported by the finding of Suja et al that states that a longer duration of treatment was one of the reasons for nonadherence to vitiligo medication. ${ }^{20}$ This sounds logical as patients with time will feel hassled about sticking to medication and be fed up from using treatments.

Moreover, we found that patients who have skin lesions in exposed areas tend to be more adherent to their treatment. A study conducted by Kandaswamy et al showed similar findings in vitiligo patients. ${ }^{21}$ Individuals with exposed skin lesions are more likely to be psychosocially affected than those with hidden lesions. 
Consequently, that will motivate them to adhere to their treatment in an attempt to cure the disease.

Subjects who reported an excellent or good patientdermatologist relationship are more likely to adhere to treatment. This point emphasizes the value of establishing a good physician-patient relationship in increasing treatment adherence (which cannot be fulfilled without proper communication skills), addressing patient concerns precisely, and considering patient preferences.

We found that patients who felt stigmatized from using their treatment are less adherent. The comparison and the worries about what other people think about them could explain their being non-adherent. Having the support of family and friends could help them to adapt more easily and minimize non adherence phenomenon. However, the psychological status of such patients should be evaluated in the dermatological setting.

In our study, non-adherence due to improved dermatological condition was one of the factors associated with treatment non-adherence. This finding is consistent with a study conducted by Suja Abraham et al ${ }^{20}$ in which the feeling that the disease is under control was documented as being one of the reasons for nonadherence to treatment in vitiligo patients. ${ }^{20}$ The patient should be informed about the necessity of continuing the treatment even if he or she feels that the condition has been cured in order to reduce relapse and the exacerbation of symptoms.

We also noticed that feeling a lack of treatment responsiveness is significantly associated with low adherence score. This was consistent with a study conducted by Sevimli et al in which unresponsiveness to medication was a common reason for discontinuation. ${ }^{31}$ Some types of dermatological treatments need a long period of time to start showing its positive effects. Thus, it might be good to carefully acknowledge patients' expectations and clarify all expected treatment outcomes to ensure the delivery of a realistic expectation and to enhance treatment adherence.

As expected, low adherence was observed in those who were not satisfied with their treatments. This is similar to the findings of another study conducted on patients with dermatological diseases. ${ }^{13}$ Therefore, it is advisable to spend adequate time with patients to address any concerns and dispel misconception related to treatments to maximize adherence to treatment. There were some limitations to this study. First, due to the length of the questionnaire, we did not include details of the dosage forms of topical medications. Second, we did not assess factors associated with each dermatological disease as separate entities.
Strengths of this study include the large sample size compared to those of the other studies in the literature. Second, multiple patient-related factors were assessed to predict possible associations with adherence to treatment in patients with dermatological diseases.

\section{Conclusion}

In conclusion, based on our analysis, treatment adherence among patients with dermatological diseases is relatively low in Saudi Arabia (44.93). Psoriasis and chronic dermatitis patients have the lowest mean adherence scores. Moreover, patients who are on topical medication have the lowest score. There are many patient-related factors associated with high adherence, including being female, not feeling stigmatized from using treatment, non-forgetfulness, connecting treatment with a habit, satisfaction with treatment, excellent patient-dermatologist relationship, lesion on an exposed area, and duration of treatment between 1 to 3 months. All of the factors could positively influence the mean adherence score. The consideration of risk factors associated with nonadherence to treatment may provide effective guidance to more successful outcomes.

\section{Ethical Approval}

All procedures performed in studies involving human participants were in accordance with the ethical standards of the institutional and/or national research committee and with the 1964 Helsinki declaration and its later amendments or comparable ethical standards."

\section{Acknowledgment}

This research project was supported by a grant from the Research Center of the Female Scientific and Medical Colleges, Deanship of Scientific Research, King Saud University. Furthermore, we would like to thank Dr. Ueno Haruka for his permission to use the 12-item medication adherence scale and the translators, Rand Al-Dakhil and Sara Bin Dakhil, for their participation in translating the 12item medication adherence scale.

\section{Author Contributions}

All authors contributed to data analysis, drafting and revising the article, gave final approval of the version to be published, and agree to be accountable for all aspects of the work.

\section{Funding}

The authors received no financial support for the research, authorship, and publication of this article. 


\section{Disclosure}

The author reports no conflicts of interest in this work.

\section{References}

1. Feldman SR, Horn EJ, Balkrishnan R, et al. Psoriasis: improving adherence to topical therapy. $J$ Am Acad Dermatol. 2008;59 (6):1009-1016. doi:10.1016/j.jaad.2008.08.028

2. Krousel-Wood M, Islam T, Webber LS, Re RN, Morisky DE, Muntner P. New medication adherence scale versus pharmacy fill rates in seniors with hypertension. Am J Manag Care. 2009;15(1):59-66.

3. Al-Qazaz H, Hassali MA, Shafie AA, Sulaiman SA, Sundram S, Morisky DE. The eight-item Morisky Medication Adherence Scale MMAS: translation and validation of the Malaysian version. Diabetes Res Clin Pract. 2010;90(2):216-221. doi:10.1016/j.diabres.2010.08.012

4. Trindade AJ, Ehrlich A, Kornbluth A, Ullman TA. Are your patients taking their medicine? Validation of a new adherence scale in patients with inflammatory bowel disease and comparison with physician perception of adherence. Inflamm Bowel Dis. 2011;17(2):599-604. doi: $10.1002 /$ ibd. 21310

5. Cutler RL, Fernandez-Llimos F, Frommer M, Benrimoj C, GarciaCardenas V. Economic impact of medication non-adherence by disease groups: a systematic review. BMJ Open. 2018;8(1):e016982. doi:10.1136/bmjopen-2017-016982

6. Torrelo A, Ortiz J, Alomar A, Ros S, Pedrosa E, Cuervo J. Healthrelated quality of life, patient satisfaction, and adherence to treatment in patients with moderate or severe atopic dermatitis on maintenance therapy: the CONDA-SAT study. Actas Dermosifiliogr. 2013;104 (5):409-417. doi:10.1016/j.ad.2012.12.003

7. Conlon NP, Edgar JD. Adherence to best practice guidelines in chronic spontaneous urticaria (CSU) improves patient outcome. Eur J Dermatol. 2014;24(3):385-386. doi:10.1684/ejd.2014.2323

8. Snyder S, Crandell I, Davis SA, Feldman SR. Medical adherence to acne therapy: a systematic review. Am J Clin Dermatol. 2014;15 (2):87-94. doi:10.1007/s40257-014-0063-y

9. Zschocke I, Mrowietz U, Karakasili E, Reich K. Non-adherence and measures to improve adherence in the topical treatment of psoriasis J Eur Acad Dermatol Venereol. 2014;28(Suppl 2):4-9. doi:10.1111/ jdv.2014.28.issue-s2

10. Richards HL, Fortune DG, Griffiths CE. Adherence to treatment in patients with psoriasis. J Eur Acad Dermatol Venereol. 2006;20 (4):370-379. doi:10.1111/jdv.2006.20.issue-4

11. Ichiyama S, Ito M, Funasaka Y, et al. Assessment of medication adherence and treatment satisfaction in Japanese patients with psoriasis of various severities. $J$ Dermatol. 2018;45(6):727-731. doi:10.1111/jde.2018.45.issue-6

12. Tan X, Al-Dabagh A, Davis SA, et al. Medication adherence, healthcare costs and utilization associated with acne drugs in Medicaid enrollees with acne vulgaris. Am J Clin Dermatol. 2013;14 (3):243-251. doi:10.1007/s40257-013-0016-x

13. Furue M, Onozuka D, Takeuchi S, et al. Poor adherence to oral and topical medication in 3096 dermatological patients as assessed by the Morisky Medication Adherence Scale-8. Br J Dermatol. 2015;172 (1):272-275. doi:10.1111/bjd.2015.172.issue-1

14. Saeki H, Imafuku S, Abe M, et al. Poor adherence to medication as assessed by the Morisky Medication Adherence Scale- 8 and low satisfaction with treatment in 237 psoriasis patients. $J$ Dermatol. 2015;42(4):367-372. doi:10.1111/jde.2015.42.issue-4
15. Doshi JA, Takeshita J, Pinto L, et al. Biologic therapy adherence, discontinuation, switching, and restarting among patients with psoriasis in the US Medicare population. J Am Acad Dermatol. 2016;74 (6):1057-1065.e1054. doi:10.1016/j.jaad.2016.01.048

16. Hsu DY, Gniadecki R. Patient adherence to biologic agents in psoriasis. Dermatology. 2016;232(3):326-333. doi:10.1159/000444581

17. Chan SA, Hussain F, Lawson LG, Ormerod AD. Factors affecting adherence to treatment of psoriasis: comparing biologic therapy to other modalities. J Dermatolog Treat. 2013;24(1):64-69. doi:10.3109/ 09546634.2011.607425

18. Evers AW, Kleinpenning MM, Smits T, et al. Treatment nonadherence and long-term effects of narrowband UV-B therapy in patients with psoriasis. Arch Dermatol. 2010;146(2):198-199. doi:10.1001/ archdermatol.2009.382

19. Kalia S, Toosi B, Bansback N, et al. Assessing adherence with phototherapy protocols. J Am Acad Dermatol. 2014;71(6):1259-1261. doi:10.1016/j.jaad.2014.07.046

20. Abraham S, Raghavan P. Myths and facts about vitiligo: an epidemiological study. Indian J Pharm Sci. 2015;77(1):8-13. doi:10.4103/ 0250-474X.151573

21. Kandaswamy S, Akhtar N, Ravindran S, Prabhu S, Shenoi SD. Phototherapy in vitiligo: assessing the compliance, response and patient's perception about disease and treatment. Indian J Dermatol. 2013;58(4):325. doi:10.4103/0019-5154.113944

22. Ueno H, Yamazaki Y, Yonekura Y, Park MJ, Ishikawa H, Kiuchi T. Reliability and validity of a 12-item medication adherence scale for patients with chronic disease in Japan. BMC Health Serv Res. 2018;18(1):592. doi:10.1186/s12913-018-3380-7

23. Bland JM, Altman DG. Cronbach's alpha. BMJ. 1997;314(7080):572. doi:10.1136/bmj.314.7080.572

24. Tsunemi Y, Abe S, Kobayashi M, et al. Adherence to oral and topical medication in 445 patients with tinea pedis as assessed by the Morisky Medication Adherence Scale-8. Eur J Dermatol. 2015;25 (6):570-577. doi:10.1684/ejd.2015.2650

25. van de Kerkhof PC, de Hoop D, de Korte J, Cobelens SA, Kuipers MV. Patient compliance and disease management in the treatment of psoriasis in the Netherlands. Dermatology. 2000;200 (4):292-298. doi:10.1159/000018390

26. Wang W, Qiu Y, Zhao F, Zhang F. Poor medication adherence in patients with psoriasis and a successful intervention. $J$ Dermatolog Treat. 2019;30(6):525-528. doi:10.1080/09546634.2018.1476652

27. Patel N, Feldman SR. Adherence in atopic dermatitis. Adv Exp Med Biol. 2017;1027:139-159.

28. Ali MA, Abou-Taleb DA, Mohamed RR. Treatment adherence and beliefs about medicines among Egyptian vitiligo patients. Dermatol Ther. 2016;29(6):413-418. doi:10.1111/dth.12397

29. Hayran Y, Incel Uysal P, Oktem A, Aksoy GG, Akdogan N, Yalcin B. Factors affecting adherence and patient satisfaction with treatment: a cross-sectional study of 500 patients with acne vulgaris. $J$ Dermatolog Treat. 2019;1-6. doi:10.1080/09546634.2019.1618434

30. Murota H, Takeuchi S, Sugaya M, et al. Characterization of socioeconomic status of Japanese patients with atopic dermatitis showing poor medical adherence and reasons for drug discontinuation. J Dermatol Sci. 2015;79(3):279-287. doi:10.1016/j.jdermsci.2015.05.010

31. Sevimli Dikicier B. Topical treatment of acne vulgaris: efficiency, side effects, and adherence rate. J Int Med Res. 2019;47 (7):2987-2992. doi:10.1177/0300060519847367 


\section{Publish your work in this journal}

Patient Preference and Adherence is an international, peer-reviewed, open access journal that focusing on the growing importance of patient preference and adherence throughout the therapeutic continuum. Patient satisfaction, acceptability, quality of life, compliance, persistence and their role in developing new therapeutic modalities and compounds to optimize clinical outcomes for existing disease states are major areas of interest for the journal. This journal has been accepted for indexing on PubMed Central. The manuscript management system is completely online and includes a very quick and fair peer-review system, which is all easy to use. Visit http:// www.dovepress.com/testimonials.php to read real quotes from published authors. 